\title{
EDITORIAL
}

\section{We are thrilled to introduce our new column: News and Views}

Light: Science \& Applications (2018) 7, 17128; doi:10.1038/lsa.2017.128; published online 12 January 2018

Cience is not only about bold findings; it is also about the scientists $\checkmark$ in the research community. In light of this observation, we are proud to introduce a new column to Light: Science and Applications (LSA): News and Views.

First published in March 2012, Light: Science and Applications has published over 300 high-quality scientific research papers and reviews and achieved an impact factor of 14.098 in 2017 (JCR 2016). While we are proud of these achievements, we are constantly looking for new opportunities to better serve our authors and readers-you, the scientists and engineers in the optics community. Hence, we conceived the idea of a brand new column featuring discussions among researchers.

In the standard Letter or Article format, our editors and peer reviewers are on the lookout for studies that are both novel and comprehensive. However, these formats make it challenging to adequately illustrate an abstract concept. In a News and Views column, an expert in a particular field will provide fresh insight into a study by using an illustration that highlights the merits of the original work. This approach will make it easier to grasp concepts quickly.

News and Views authors will provide not only insight into the selected topic but also an overview of the relevant field and an outlook on future developments. Unlike a Review, which aims to provide a broad overview of a topic, News and Views columns will be considerably more concise, which will make them easier to read and write. We hope that our readers will enjoy these timely updates of the month's most exciting topics.
Whereas real-estate agents have the slogan 'location, location, location', here at Light: Science and Applications, we are all about 'communication, communication, communication'. Our aim is to foster discussions among researchers, and News and Views will provide a window onto a topic from a new and independent perspective. We have also organized the Light Conference series, which takes place in the beautiful home of Light: Science and Applications-Changchun. This conference provides our community-authors, readers, and editors-with a great opportunity to gather and communicate in person. Finally, we are on Facebook and Twitter. Please follow us and share your thoughts and ideas. Let's work together to shape the future of optics.

Peng Xi

Department of Biomedical Engineering, College of Engineering Peking University No. 5 Yiheyuan Road, Beijing 100871, China Email: xipeng@pku.edu.cn

\footnotetext{
(c) (i) (2) This work is licensed under a Creative Commons AttributionBY NC SA NonCommercial-ShareAlike 4.0 International License. The images or other third party material in this article are included in the article's Creative Commons license, unless indicated otherwise in the credit line; if the material is not included under the Creative Commons license, users will need to obtain permission from the license holder to reproduce the material. To view a copy of this license, visit http:// creativecommons.org/licenses/by-nc-sa/4.0/
}

(C) The Author(s) 2018 